\title{
A Needs Assessment For Indigenous African Language-Based Programming Languages
}

\author{
Ezekiel K. Olatunji ${ }^{1}$, John B. Oladosu' ${ }^{1}$, Odetunji A. Odejobi ${ }^{2}$, Stephen O. Olabiyisi ${ }^{1}$
}

${ }^{1}$ Department of Computer Science and Engineering, Ladoke Akintola University of Technology, Ogbomoso, Nigeria

${ }^{2}$ Department of Computer Science and Engineering, Obafemi Awolowo University, Ile-ife, Nigeria

Received $7^{\text {th }}$ Mar. 2019, Accepted 22 $2^{\text {nd }}$ Aug. 2019

DOI: 10.2478/ast-2019-0007

*Corresponding author

Ezekiel K. Olatunji E-mail: aekolatunji@gmail.com

Tel: $+234(0) 8038580770$

\begin{abstract}
The development of an African native language-based programming language, using Yoruba as a case study, is envisioned. Programming languages based on the lexicons of indigenous African languages are rare to come by unlike those based on Asian and / or European languages. Availability of programming languages based on lexicons of African indigenous language would facilitate comprehension of problem-solving processes using computer by indigenous learners and teachers as confirmed by research results. In order to further assess the relevance, usefulness and needfulness of such a programming language, a preliminary needs assessment survey was carried out. The needs assessment was carried out through design of a structured questionnaire which was administered to 130 stakeholders in computer profession and computer education; including some staffers and learners of some primary, secondary and tertiary educational institutions in Oyo and Osun states of Nigeria, Africa. The responses to the questionnaire were analyzed using descriptive statistics. The analysis of the responses to the questionnaire shows that $89 \%$ of the respondents to the questionnaire expressed excitement and willingness to program or learn programming in their mother tongue-based programming language, if such a programming language is developed. This result shows the high degree of relevance, usefulness and needfulness of a native language-based programming language as well as the worthwhileness of embarking on development of such a programming language.
\end{abstract}

Keywords: Programming languages, Native language-based programming languages, Lexicons, Linguistic genocide, Problem-solving processes. 


\subsection{Introduction}

Programming languages (PL) are notations for description of algorithms and data structures to computers and people. The design and evolution of programming languages (PLs) have always been influenced by a number of factors including discovery of weaknesses and/or deficiencies in the existing PLs; development in computer hardware; requirements of new areas of application; changing understanding of better methods of writing and maintaining large and complex programs; understanding of strength and weakness of some language features and the need for standardization (Olatunji, 2014).

Most of the existing popular high-level programming languages (such as Visual Basic, Java, C++) in the continent of Africa borrowed their lexical items from English language. There are also literatures on PLs that borrowed lexical items from Asian languages, such as Rapira (Cockett, 2007; Dadhich, 2006) and Ezhil(Annamalia,2013). However, there is little or no research information on serious attempt at design and implementation of programing languages whose lexical items are borrowed from words of indigenous African languages. According to Olatunji, et al (2018), development of PLs based on the lexicons of African indigenous languages will improve computer-based problem-solving processes by indigenous teachers and leaners. This fact has also been confirmed by research studies (UNESCO, 2007; Pflepsen, 2011; Ball 2010).

A work in progress on development of a native language-based programming language has been reported by Olatunji et al (2018). This present study was embarked upon in order to further seek the opinions of stakeholders in computer programming and computer education as to the relevance, needfulness and usefulness of a native language-based programming language for introducing computer programming, especially at the elementary and junior secondary schools.

\subsection{Related Works}

According to Jannetti (2012), a needs assessment can be described as a systematic procedure of gathering information that is appropriate and sufficient to develop an effective educational program that will address a group's needs and wants. A needs assessment has been carried out by various organizations for various domains.

The Young Women Christian Association (YWCA) of Canada carried out a project intended to prevent and eliminate cyber violence against young women and girls across Canada (Alma and Meyer, 2015). In order to accomplish this project a gender-based needs assessment was carried out. The needs assessment data were gathered through interviews and online survey. Seventeen (17) people were interviewed while 88 people responded to the online survey. From the analysis of the needs assessment, a number of needs were identified, including but not limited to building of knowledge and skills for girls and young women; such as more understanding of what cyber violence is and computer literacy skills. A number of recommendations were also made to stakeholders, such as educational institutions, parents, teachers, Police and others. In the conduct of our own needs assessment, only a survey through questionnaire was employed in order to assess the needfulness of a native language-based programming language.

A needs assessment in the teaching of Indonesian language as a second/foreign language e-learning program was conducted by Nugraha et al (2018). The needs assessment was required to help teachers to analyze the learning materials, content and medium for their e-learning program. Data for the needs assessment were gathered through interview and document study. Interviews were conducted for the program developers, teachers IT support group and research and development (R\&D) team. As a result of the needs assessment carried out, new learning materials were developed and given to every leaner that enrolled in the e-learning program. Unlike the methodology employed in this needs assessment, our own needs assessment was conducted through administration and analysis of questionnaire.

The International Organization for Migration (IOM), Abuja, Nigeria conducted a needs assessment survey of the education sector in Nigeria in 2014 (IOM, 2014). The goal of the assessment was to provide Government with recommendations on how identified skill and competency gabs in education could addressed. Methods used for data collection included review of extant relevant needs assessments documents in the education sector, a survey questionnaire responded to by relevant government officials and semi-structured interviews with executives of commissions and agencies that have oversight functions for the three strata of Nigerian education sector. Among others, the result of the needs assessment conducted by IOM revealed acute skill gabs in the core disciplines of Science, Mathematics, foreign language and basic technology at the secondary educational levels, while skill shortage in the tertiary institutions include Science, Engineering, Medicine and special education. Based on the results of the assessment, it was recommended that the Government, tertiary educational institutions and other stakeholders in education sector should explore diaspora virtual participation as an intervention strategy for the tertiary institutions.

In 2018, the United Way of Wyandotte County conducted a needs assessment of their county as a result of a number of issues of concern including child abuse, neglect and support for families (University of Kansas, 2018). For each of these areas of concern, they used various methods such as survey and secondary data (such as US population and housing census). From the analysis of the survey conducted, most of the respondents were not satisfied with the way those issues of concern were being addressed in the county. Potential solutions suggested by respondents, who are also community members included providing help in the home, providing support and information for families through churches, hotlines, and providing information on other available means.

\subsection{Methodology}

A need survey on development of a native-language-based programming language was carried out through design of a structured questionnaire. The questionnaire was administered to some staffers and students of some primary, secondary and tertiary educational institutions in Oyo and Osun states of Nigeria. The responses to the questionnaire were also analyzed. Simple percentage (\%) was used for the analysis.

\section{Structure of the Questionnaire}

The needs assessment for a native language-based programming language (NLPL) was intended to answer three main questions, which are:

i) Are there any positive benefits of having a NLPL?

ii) Are there any negative implications of not having a NLPL? 
iii) What are the likely responses / reactions to existence / development of a NLPL?

Aside asking for background information on occupation and computer programming knowledge the questionnaire has two main sections. The first section consisted of seven views of the author on the positive effect of having a PL based on the lexicons of any of the major Nigerian languages. Respondents were required to express their opinions by rating each of the seven views on a 5 point Likert scale of strongly agree, agree, neutral, disagree, and strongly disagree. The second section contained five statements on the possible negative impact of not having a NLPL. Each of this view was also rated by respondents on a 5-point likert scale as for the first section.

\section{Population Distribution of the Questionnaire}

The questionnaire was administered to ten different groups of people within Oyo and Osun states of Nigeria. Oyo state, Nigeria is where the original Yoruba language, the language of our case study of African indigenous language, is spoken and it is this version of Yoruba that was formulated as the standard Yoruba. Osun state was formerly part of Oyo state. The group to which questionnaires were administered consists of certified Computer Scientists and Computer Science students from both public and private Universities, Teachers of both public and private secondary and primary schools in a big town and a semi-rural town as well as students and pupils of these secondary and primary schools. Out of 130 copies of the questionnaire administered, only 117 could be retrieved from the respondents. Thus the response rate amounts to $90 \%$. The 117 respondents consist of the following:

a) 8 certified computer scientists, working as Lecturers and Technologists in a private University in Osun state

b) 17 Computer science students from a public University in Oyo state. Public university is a mixture of students of both the poor and elites in the society, depending on their ability to compete for the few available vacancies in Nigeria public Universities.

c) 31 Computer Science students from a private University in Osun state. Most of the students are children of the elites/rich people, and they mostly speak English more than their mother tongues

d) 13 teachers of a public Junior secondary school in a rural area in Osun state

e) 7 Teachers of a private secondary school in a town in Iwo LGA of Osun sate

f) 5 Teachers of a public primary school in a village in Ayedire LGA of Osun State

g) 10 students from a private secondary school in Iwo town, Osun state. These are usually children of elites in which medium of communication is more of English than the native language h) 7 students from one public school in a rural area. Such schools are more commonly attended by children of non-elites in the community; and they are more proficient in their native language

i) 9 students from another public secondary school in a village in Ayedire LGA of Osun state

j) 10 pupils from a private primary school in a semi-rural town in Ayedire LGA of osun state. Such a school is attended by children of the elites in the community and they mostly communicate in English even at home.

Respondents in categories $\mathrm{a}, \mathrm{b}$ and $\mathrm{c}$ are not only computer literate but are also experienced in Computer programming. Respondents in categories d, e and $f$ are matured experienced teachers, some of which are computer literate but are not necessarily having programming knowledge. Some respondents in categories $\mathrm{g}, \mathrm{h}, \mathrm{i}$ and $\mathrm{j}$ may have some ideas about computer but definitely have no knowledge in computer programming. Most of the respondents from junior secondary schools and primary schools were assisted by their class teachers in responding to the questionnaires.

\subsection{Results and Discussion}

The analysis of the result of preliminary needs survey of a native-languagebased PL (NLPL) carried out through structured questionnaire shows that many people in Nigeria (both computer literates and those not too literate in computer) are willing to program or learn programming in their mother tongues. More specifically, $89 \%$ of the respondents to the questionnaire expressed excitement and would be willing to program or learn programming in a mother-tongue-based programming language, if such a language is available or is developed. This result indicates high degree of relevance and usefulness of a NLPL.

The result of the analysis of responses to the questionnaire is more succinctly presented in Table 1 and graphically shown in Figure 1. Table 1 contains the detail responses of different category of respondents (Column 1 of Table 1 ).

In Figure 1, for each category of respondents, the blue bar indicates the percentage of those who expressed willingness to program in a NLPL, while the red bar shows the percentage of those not interested in programming in a NLPL.

From Table 1, 86\% (48/56) of the respondents who are knowledgeable in computer programming expressed excitement and willingness to program in a NLPL, if one is developed. These 56 respondents to the questionnaire consist of 8 certified computer scientists working in a tertiary institution (an accredited private University), and 48 computer science students in one public university and one private university. Eighty-four ( $84 \%$ that is 21 out of 25) of the adult respondents (certified teachers in secondary and primary schools) who are less knowledgeable in programming expressed excitement at a NLPL and are willing to learn programming and program in such a PL. 
Table 1: Summary of Analysis of Responses to the Questionnaire on the Need for a NLPL

\begin{tabular}{|l|l|l|l|l|l|l|l|}
\hline Respondent Category & $\begin{array}{l}\text { Total } \\
\text { Population }\end{array}$ & $\begin{array}{l}\text { PL } \\
\text { Knowledge } \\
\%\end{array}$ & $\begin{array}{l}\text { NLPL } \\
\text { Knowled } \\
\text { ge } \\
\%\end{array}$ & $\begin{array}{l}\text { Excitement at } \\
\text { NLPL \% }\end{array}$ & $\begin{array}{l}\text { Indifferent to } \\
\text { NLPL\% }\end{array}$ & $\begin{array}{l}\text { Like to } \\
\text { Program in } \\
\text { NLPL \% }\end{array}$ & $\begin{array}{l}\text { Won't Program in } \\
\text { NLPL\% }\end{array}$ \\
\hline Certified Computer Scientists & 8 & $100 \%$ & $0 \%$ & $75 \%$ & $25 \%$ & $75 \%$ & $25 \%$ \\
\hline Computer Science Students & 48 & $100 \%$ & $0 \%$ & $77 \%$ & $23 \%$ & $87.5 \%$ & $12.5 \%$ \\
\hline Teachers in Sec \& Pry Schools & 25 & $56 \%$ & $4 \%$ & $84 \%$ & $8 \%$ & $84 \%$ & $16 \%$ \\
\hline Secondary School Students & 26 & $77 \%$ & $0 \%$ & $81 \%$ & $15 \%$ & $96 \%$ & $4 \%$ \\
\hline Primary School pupils & 10 & $0 \%$ & $0 \%$ & $70 \%$ & $0 \%$ & $100 \%$ & $0 \%$ \\
\hline Total Respondent & 117 & $77 \%$ & $0.8 \%$ & $79 \%$ & $16 \%$ & $89 \%$ & $11 \%$ \\
\hline
\end{tabular}

Note: $\mathrm{PL}=$ Programming Language, $\mathrm{NLPL}=$ Native language-based programming language

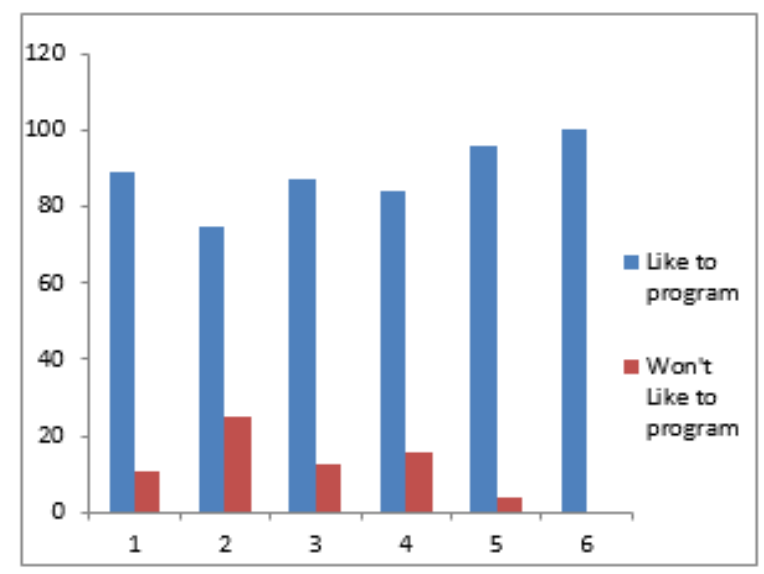

\begin{tabular}{|l|l|}
\hline Key to Horizontal S/No \\
1. Total Population \\
2. Computer Scientists \\
3. Computer Science \\
Undergraduates \\
4. Sec \& Pry School \\
Teachers \\
5. Sec School Students \\
6. Pry School Pupils
\end{tabular}

Figure 1: Result of Needs Assessment

From Figure 1, the result of the needs assessment shows that more people in each category of respondents are willing to program or learn programming in a NLPL, if one exists or is developed.

Reasons given by six (6) out of eight (8) certified computer scientist who are willing to program in a NLPL include:
a) It will make programming natural
b) It will enhance programming skill
c) Will enhance programming pedagogy
d) Make one's thought to be easily relayed in programming space
e) Process of coding will be easy as creativity will be at play in the language understood very well.
f) it will make teaching and learning of programming, to children, especially in rural areas, very easy

Four (4) out of 56 respondents who are knowledgeable in computer programming but are not interested in programming in native languagebased programming language gave no reason for their unwillingness. The reasons given by the remaining four in this category and others not willing to program or learn programming in a NLPL include: i) I can hardly read in my mother tongue

ii) I am used to communicating in English all of my life

iii) No Nigerian language is my mother tongue.

\subsection{Conclusion}

The excitement and willingness expressed by majority (89\%) of the respondents to the questionnaire on the need survey for native languagebased programming language (NLPL) to program or learn programming in NLPL is an attestation to the high degree of relevance needfulness and usefulness of developing a NLPL. This result is a good reason researchers in Africa should embark on study in development of indigenous African language-based Programming Language. Furthermore, the need to facilitate better comprehension of problem-solving process using computer by indigenous learners and teachers, as confirmed by research studies, is another key reason for embarking on such study.

In addition, the need to empower more people who are only literate in their native languages to learn computer programming is a worthwhile reason for attempting the development of a mother tongue-based programming language. Development or availability of such programming languages will serve as an effective strategy to: 
i) prevent predicted linguistic genocide of indigenous African languages (Benson, 2006, Azeez, 2013)

ii) ensure the continuity and relevance of indigenous languages in the age of ICT and increasing globalization

iii) bridge the digital divide between the developed and underdeveloped/developing countries of the world (Wagner, Daswani and Karnati, 2010; Pflepsen 2011)

\section{Authors Contribution}

Conception: [E.K.O, J.B.O, O.A.O, S.O.O]

Design: [E.K.O, J.B.O, O.A.O, S.O.O]

Execution: [E.K.O]

Interpretation: [E.K.O, J.B.O, O.A.O, S.O.O]

Writing of the paper: [E.K.O]

\section{References}

Alan, E., Meyer, M., 2015, Project Shift: Creating a safer digital world for young women. Retrieved on 05-07-2019 from www.ywcacanada.ca

Annamalia, M., 2009, Ezhil - A Tamil programming language. Retrieved from arxiv.org/pdf/0907.4960 On 17-03-2015

Annamalia, M., 2013, Invitation to Ezhil: A Tamil Programming Language for Early Computer Science Rducation; Retrieved from http://ezhillang.org on 17-03-2015

Azeez, A.S., 2013, The Yoruba language and Literature in the $21^{\text {st }}$ Centuary and beyond, Covenant Journal of language Studies (CJLS). 1 (2): 148-159.

Ball, J., 2010, Enhancing learning of children from diverse language backgrounds: Mother tongue-based bilingual or multilingual education in the early years, UNESCO. Available online athttp://unesdoc.unesco.org/images/0018/001869/186961e.pdf.Retrie ved on 30-07-2014

Benson, C., 2006, "Mother Tongue First". Available on line at www.multicultures.comRetrieved on 30-07-2014

Cockelt, J.R.B., 2007, Notes on Code Generation. Available online at pages.cpsc.ucalgary.ca/ robin/class/510/cg-expression.pdf. Retrieved on 16-06-2015.

Dadhich, B.S., 2006, Needed: A good 'Hindawi Programming Language'. Retrieved on 15-06-2015 from www.localisationlabs.balendu.c om/

Fabunmi, F. A., Salawu, A.S., 2005, Is Yoruba an Endangered Language, Nordic Journal of African Studies. 14(3):391-408. Available atwww.njas.helsinki.fi/.../fabunmi.pdfRetrieved on 28-01-2015.

International organization for Migration, 2014, Needs Assessment in the Nigeria Education Sector, IOM, Abuja, Nigeria. Retrieved on 10-0719 from https://reliefweb.int/report/nigeria/

Jannetti, A. J., 2012, A Representation incorporating a Needs Assessment and Gap Analysis into the Educational Design. Pitman, New Jersey. Available on https://www.suna.org/events/needsAssessment.pdf Retrieved 10-07-2019.

Nugraha, S.T., Suwandi, S., Nurkantr, J., Saddho, K., 2018, The Importance of Needs Assessment for the Implementation of E-learning in a Language program. KnE Social Sciences, 3(9): 254-260. Retrieved on 10-07-2019 from https://knepublishing.com

Olatunji, E.K., Oladosu, J.B., Odejobi, O. A., Olabiyisi, S.O., 2018, Towards Development of an Indigenous African Language-based

5| This journal is @ The Nigerian Young Academy 2019
Programming Language, FUOYE, Journal of Engineering and Technology (FUOYEJET). 3(2): 61-64.

Olatunji, E. K., 2014, Programming Languages - Introductory Text on Concepts and Principles, Ilorin - Nigeria, Igbagbogbemi Publishers ISBN 978-187-458-9, 8.

Pflepsen, A., 2011, Improving Learning Outcomes through Mother Tongue-Based Education, , MTB-MLE Network. Available online at https://www.eddataglobal.org Last Accessed on 30-07-2014, stored online as eddata_ii_mother_tongue_instruction.pdf 1 (2): 148-159, Dec 2013.

UNESCO, 2007, Mother Tongue-based Literacy Programmes: Case Studies of Good Practice in Asia. Bangkok: UNESCO Bangkok, Thailand, ISBN 92-9223-113-8 Available online at www.unesdoc.unesco.org Retrieved on 30-07-2014

University of Kansas, 2018, Needs Assessment Example: Wyandotte county. Available online at https://ctb.ku.edu/en/assessingcommunity-needs-and-resources/ Retrieved on 05-07-2019.

Wagner, D. A., Daswani, C. J., Karnati, R., 2010, Technology and MotherTongue Literacy in Southern India: Impact Studies among Young Children and Out-of-School Youth Creative Commons AttributionNon Commercial-Share Alike 3.0. Winter. 6 (4): 23-43. Available online at www.itidjournal.org Last accessed on 30-07-2014 